\title{
EDITORIAL
}

\section{IMAGEN Y REPRESENTACIÓN DE FRONTERAS Y PUEBLOS INDÍGENAS ANDINOS. HISTORIA, ANTROPOLOGÍA Y NUEVOS ENFOQUES*}

\author{
IMAGE AND REPRESENTATION OF BORDERS AND INDIGENOUS ANDEAN \\ PEOPLE. HISTORY, ANTHROPOLOGY AND NEW APPROACHES
}

\author{
Rodrigo Ruz Zagal ${ }^{* *}$ \\ Luis Galdames Rosas ${ }^{* * *}$
}

\begin{abstract}
La necesidad de humanizar los espacios donde se representa -e investiga- la sociedad y la cultura, ha sido parte del debate transversal en el ámbito de las ciencias sociales y humanas desde la segunda mitad del siglo XX hasta el presente.

Los orígenes de la revista Diálogo Andino como espacio de discusión, debate y divulgación del conocimiento resultante de investigaciones, posee esta impronta desde fines de la década de 1970, momento en el que la Historia y Antropología del norte chileno asume y hace propias discusiones y enfoques generadores de cambios en la escena mundial en cuanto otorgar visibilidad y abordaje a problemáticas atingentes a las peculiaridades culturales observables en la región andina.
\end{abstract}

Este desarrollo temprano a nivel disciplinar, pretendió profundizar y visibilizar problemáticas ancladas a contingencias regionales con acento tanto en el presente como en el pasado de la sociedad, cultura y humanidad andina otorgando a la antropología (con acento en la arqueología), $\mathrm{y}$ en menor forma a la historia, una madurez en comparación a otras especialidades en ciencias sociales y humanistas, destacando en este contexto el notable desarrollo de los Estudios Andinos cultivados hasta hoy en Perú, Argentina, Bolivia y Chile (Zanolli et al. 2013).

A saber, el desarrollo desde la década de 1970 de temáticas y tesis arqueológico-antropológicas en torno a la multietnicidad, identidades territoriales y culturales, movilidad, entre otras, que posteriormente devinieron en escalamientos hacia la etnohistoria como resultante del vínculo entre la arqueología, etnología e historia, permitió que a fines de 1980 y durante la década de 1990 nuevas problemáticas se posicionaran dentro del espectro de los estudios andinos ya con un marcado acento histórico-etnológico: relaciones de comunidades indígenas-estado colonial, fenómenos de agencia, resistencia, asimilación y apropiación cultural en este contexto, desarrollo de temáticas en torno a género, tecnologías y cosmovisión andinas, entre otras (Gundermann y González 2009, Núñez 2013, Hidalgo et al. 2013).

El siglo XXI encuentra una antropología social y cultural parcialmente escindida de la arqueología, mientras que la historia del norte chileno posee una profunda impronta antropológica que reconoce en la cultura y sus particularidades, un foco de desarrollo que permite el impulso a programas de investigación vigentes concentrados en problemas y enfoques histórico-culturales, tales como: identidades nacionales y sus alteridades, emergencia de lo étnico en contextos de conflicto nacional, relaciones fronterizas y transfronterizas, entre otras (Galdames 1999, Morong 2014, Díaz et al 2015).

Quizás sea el acercamiento históricoantropológico el que mejor refleje la recepción de ciertos paradigmas tanto teóricos como metodológicos que en estas especialidades poseen una discusión vigente a nivel mundial, fundamentalmente en lo que respecta a la

\footnotetext{
* Proyecto FONDECYT 1151514, Proyecto de Investigación Mayor de Ciencia y Tecnología UTA 5736-15 y Convenio de Desempeño en Educación Superior Regional UTA 1401, Ministerio de Educación y la Universidad de Tarapacá.

** Universidad de Tarapacá. Departamento de Ciencias Históricas y Geográficas. Director Archivo Histórico Vicente Dagnino, Arica, Chile. Correo electrónico: rruz@uta.cl.

*** Universidad de Tarapacá. Departamento de Ciencias Históricas y Geográficas, Arica, Chile. Correo electrónico: lgaldame@uta.cl
} 
superación de supuestas rigideces disciplinarias para permitir comprender al hombre en sus acepciones culturales y humanas, su vida en sociedad, no descuidando su historicidad.

El número de Diálogo Andino que se presenta, concentra su énfasis en una parte de la comunidad académica especialista que desarrolla su labor investigativa preferentemente en y con población indígena de los Andes, o en su defecto, en espacios de frontera (territorial y cultural) dentro del área centro sur andina, poniendo su centro en los estudios de materialidades, objetos, sujetos, métodos y teorías dialogantes con lo que se puede denominar estudios de la representación, apelando a la posibilidad y práctica teórica que indica que la cultura y la sociedad se representa, comprende, vehiculiza y circula (Szurmuk y Mckee 2009).

Se trata de trabajos en los que la reflexión teórica y acción metodológica subyacentes poseen una densidad que atraviesa y trasciende diversas especialidades que, soportadas de modo preferente sobre la historia y la antropología, escalan y cruzan sus límites derivando a los estudios visuales y de la imagen, estética, estudios culturales, historia del arte o antropología visual; manifestando así la necesidad de contar con espacios multi y transdisciplinares -así como grupos e investigadores con estas características- que aborden problemáticas comunes con una vocación integradora aunque cautelosa de la segmentación de las realidades en pro de la especialidad (Osorio 2005).

Esta característica perfila a este compendio como un espacio congregador no solo de especialistas, sino que de tradiciones investigativas que escalan por sobre los esquemas tradicionales de entender y comprender al hombre andino, su espacio de asentamiento y desenvolvimiento, así como su interacción con estructuras de poder estatal y hegemonías culturales. Ello, atendiendo a que la totalidad de autores convocados aborda la representación visual de estos, teniendo como objeto o sujeto de análisis la imagen en diversos soportes, que reconocen un notorio marco históricoantropológico basal.

La tensión epistemológica subyacente en esta forma de entender e investigar el mundo, esto es, bajo un paralelismo que da cuenta de una "realidad" y su representación, entendida como una segunda realidad "espejada", mas no original; ha derivado en la emergencia -díscola en materia disciplinaria- de miradas consonantes y disonantes que han abierto posibilidades de investigación surgidas desde los cuestionamientos de las disciplinas centrales, provocando fraccionamientos virtuosos que se concentran en los defectos epistemológicos manifiestos en las estructuras tradicionales de exploración científica, aunque sin escapar por ello de la crítica y la subvaloración.

En este tono, viejos materiales han vuelto a ser leídos y sometidos a nuevos marcos teóricos e incluso nuevos métodos, permitiendo con ello revitalizar performances académicas necesitadas de nuevas miradas.

En Chile las miradas renovadoras respecto del canon tradicional son visibles en prácticas investigativas y programas de investigación, así como también en la formación académica de postgrado en instituciones que desarrollan su quehacer bajo este paradigma.

Constante es el trabajo realizado por José Luis Martínez respecto de la construcción de identidades, imaginarios coloniales y su intertextualidad con materialidades de carácter inconográfico; aspectos que de una u otra forma han traspasado al programa de Doctorado en Estudios Latinoamericanos de la Facultad de Humanidades de la Universidad de Chile desde donde han egresado jóvenes doctores que despliegan sus inquietudes hacia los nuevos paradigmas, sin dejar de lado la impronta etnológica e histórica.

Además, desde el Instituto de Estética de la Pontificia Universidad Católica de Chile se han levantado distintos proyectos de investigación con financiamiento FONDECYT en torno a la imagen y la representación del mundo indígena, destacándose las investigaciones desarrolladas por Margarita Alvarado, Carla Möller, Christian Báez y María Paz Bajas.

Con una trayectoria de más de 15 años la Revista Chilena de Antropología Visual, cuyo primer número se publica el año 2001 y el Centro de Estudios en Antropología Visual, fundado en 2011, ambas instancias independientes, pero continuadoras de prácticas investigativas llevadas a cabo por el Núcleo de Antropología Visual de la Academia de Humanismo Cristiano, otorgan cabida a investigadores e investigaciones en torno a la imagen y visualidades, destacando en su quehacer académico y editor los investigadores Pedro Mege, Gastón Carreño, María Paz Bajas, Felipe Maturana, Viviana Gallardo, Damián Duque, Samuel Linker y Francisca Pérez, entre otros. 
Al alero del Archivo Etnográfico de la Universidad de Chile, la labor investigativa de su Director André Menard respecto de la representación y noción de raza con foco en lo mapuche, ha dado saltos hacia su representación en imágenes fotográficas sin perder la mirada de archivo, aspecto que de una $\mathrm{u}$ otra forma lo vincula al quehacer de Claudio Mercado desde los archivos de videos etnográficos del Museo Chileno de Arte Precolombino.

La Universidad Alberto Hurtado desde el año 2012 imparte el programa académico de Magíster en Estudios de la Imagen, propuesta interdisciplinaria que integra distintas perspectivas de análisis en torno a la imagen, abarcando ámbitos como la iconología, la filosofía de la imagen, los estudios sobre la imagen técnica y las complejas relaciones entre palabra e imagen. De esta universidad el trabajo desarrollado por Marisol Palma relativo a indígenas fueguinos sobre la base de las fotografías de Martín Gusinde, explora aspectos biográficos de la fotografía como objeto, así como también de quien fotografía y del que se representa, abriendo con esto espacio al mundo indígena a dicho programa.

En Centro Nacional de Patrimonio Fotográfico patrocinado por la Universidad Diego Portales aporta como un importante archivo de la materialidad y práctica fotográfica nacional, sin descuidar la mirada regional; desde esta óptica iniciadora del equipo constituido por Ilonka Csillag, Hernán Rodríguez, Roberto Aguirre, hoy continuado por Samuel Salgado y Andrea Aguad, otorgan una densidad a la investigación de la práctica fotográfica.

El programa de Doctorado en Antropología emprendido por la Universidad de Tarapacá y Universidad Católica del Norte también ha aportado respecto de la formación de doctorandos que desde diversas perspectivas han venido trabajando la imagen y el espacio fronterizo con foco en problemáticas visibilizadas desde la propia región fronteriza, por medio de registros y materialidades levantadas desde lo local. En este tenor destacan los enfoques antropológico-visuales de Andrea Chamorro y Juan Pablo Donoso, y desde una perspectiva histórico-cultural el trabajo desplegado sobre materialidad documental e imágenes desarrolladas por el equipo dirigido por Luis Galdames, que ejecutando proyectos de investigación financiados por FONDECYT evalúan aspectos de identidades y alteridades nacionales en espacios fronterizos, teniendo como soporte medios de comunicación masivos de carácter histórico con notable componente visual.

En justicia, debemos mencionar que este dossier tuvo su génesis durante las XX Jornadas de Historia de Chile, realizadas el año 2013 organizadas por las universidades nortinas que desarrollan su labor tanto en Arica como en Iquique (Universidad de Tarapacá y Universidad Arturo Prat). En dicho evento se convocó una mesa denominada Visualidades, representaciones e imaginarios de la frontera norte chilena. Enfoques interdisciplinarios, que tenía por finalidad discutir respecto del pasado y la representación del espacio nortino desde una perspectiva multidisciplinar, esto es, considerando diversas miradas a un mismo "problema": el norte, su gente y su espacio. En dicha ocasión se congregó a Margarita Alvarado, María Paz Bajas, Josefina de Maza y Felipe Maturana, además de Rodrigo Ruz editor del presente número que hoy se revela y que cuenta con aportes de diversos actores que de alguna manera u otra dan cuenta del estado del arte en cuanto la importancia de la imagen en este escenario.

Estimamos que el esfuerzo intelectual que supone proponer nuevas miradas colectivas es pertinente y necesario, sin desconocer que el camino recorrido trae consigo desafíos teóricos y metodológicos de difícil resolución, pero precisamente por ello despiertan nuevas alianzas disciplinarias y arroja inéditas luces a las veredas del pensamiento que se han de transitar.

\section{Referencias Citadas}

Díaz, A.; Morong, G. y Mondaca, C.

2015 Entre el archivo y la etnografía. Reflexiones historiográficas desde la periferia del Norte de Chile. Diálogo Andino 46: 107-121.

Galdames, L.

1999 El ámbito de "lo local" como perspectiva de análisis de los pueblo andinos del norte de Chile. Diálogo Andino: 9-19.
Gundermann, H. y González, H.

2009 Sociedades indígenas y conocimiento antropológico. Aymaras y atacameños de los siglos XIX y XX. Chungara, Revista de antropología chilena 41 (1): 113-164.

Hidalgo, J.; Castro, N. y Aguilar, J.

2013 Historia de los pueblos andinos de Arica, Tarapacá y Atacama. En Los estudios andinos hoy. Práctica intelectual y estrategias de investigación. C. Zanolli, J. Costilla, 
D. Estruch y A. Ramos (compiladores). Pp. 243-276. Prohistoria, Argentina.

Morong, G.

2014 De la historiografía nacional a la historia de los bordes. Violencia epistémica y emergencia de lo subalterno en el contexto de la chilenización del Norte Grande; siglos XIXXX. En Tiempos violentos. Fragmentos de historia social en Arica. A. Díaz, R. Ruz y L. Galdames (compiladores). Pp. 11-22. Ediciones Universidad de Tarapcá, Chile. Núñez, L.

2013 Sobre los comienzos de los estudios andinos y sus avances actuales en el Norte de Chile. En Los estudios andinos hoy. Práctica intelectual y estrategias de investigación.
C. Zanolli, J. Costilla, D. Estruch y A. Ramos (compiladores). Pp. 79-122. Prohistoria, Argentina.

Osorio, F.

2015 Modelos multidisciplinarios para las ciencias sociales. Persona y Sociedad. Volumen XIX (2): 143-159.

Szurmuk, M. y Mckee, R.

2009 Estudios Culturales Latinoamericanos. Siglo XXI: Instituto Mora, México.

Zanolli, C.; Costilla, J.; Estruch, D. y Ramos, A.

2013 Presentación. En Los estudios andinos hoy. Práctica intelectual y estrategias de investigación. C. Zanolli, J. Costilla, D. Estruch y A. Ramos (compiladores). Pp. 9-18. Prohistoria, Argentina. 